\title{
An Unusual Presentation of Parvimonas micra Infective Endocarditis
}

\author{
Dawn Ho ${ }^{1}$, Grace Ang ${ }^{1}$, Chaozer Er ${ }^{2}$, Siew Fei Yap ${ }^{3}$, Veeraraghavan Meyyur Aravamudan 4 \\ 1. Internal Medicine, MOH Holdings, Singapore, SGP 2. Internal Medicine, Woodlands Health Campus, Singapore, SGP \\ 3. Cardiology, Yishun Health, Singapore, SGP 4. Internal Medicine, Woodlands Health Care, Singapore, SGP
}

Corresponding author: Dawn Ho, dawn.ho@mohh.com.sg

\begin{abstract}
Parvimonas micra has been identified as a prominent oral pathogen. This organism has been implicated in periodontal, soft tissue and bone infections. It causes a subacute presentation with high morbidity. We present a case of severe infective endocarditis caused by Parvimonas micra requiring valvular surgery despite appropriate antibiotics. To our knowledge, this is the second case report of Parvimonas micra infective endocarditis since its reclassification in 2006.
\end{abstract}

Categories: Cardiology, Internal Medicine, Infectious Disease

Keywords: parvimonas micra, endocarditis, peptostreptococcus, anaerobic bacteria

\section{Introduction}

Parvimonas micra is an anaerobic Gram-positive coccus. Anaerobic bacteria have been linked to severe complications of infective endocarditis (IE) such as mycotic aneurysms, septic emboli, valvular destruction, and septic shock [1]. IE due to anaerobic bacteria is uncommon, accounting for $2-16 \%$ of all cases of IE over the past few decades. However, the Parvimonas species in particular is noted in a select group of patients predisposed with prosthetic valves, dental procedures and infections, septic arthritis, or genitourinary infections [1].

In this case, we describe a 42-year-old Malay gentleman with a mitral valve replacement, who presented with recurrent fever after a tooth extraction. He was diagnosed to have Parvimonas micra infective endocarditis.

This is the second case report of Parvimonas micra causing IE in humans since the organism, originally known as Peptostreptococcus micros, was transferred to the Micromonas genus in 1999 [2], then reclassified within the Parvimonas genus in 2006 [2, 3]. We reviewed the literature in the context of this uncommon infection. We included in our literature review species formally classified as Peptostreptococcus species.

Received 08/27/2018

Review began 09/02/2018 Review ended 09/16/2018 Published 10/13/2018

○) Copyright 2018

Ho et al. This is an open access article distributed under the terms of the Creative Commons Attribution License CC-BY 3.0., which permits unrestricted use, distribution, and reproduction in any medium, provided the original author and source are credited.

\section{Case Presentation}

A 42-year-old Malay gentleman, with significant past medical history of diabetes mellitus and mechanical mitral valve replacement (MVR) (St. Jude Medical Masters $29 \mathrm{~mm}$ ) due to Staphylococcal endocarditis in 2015, on lifelong anticoagulation with warfarin, was first admitted for a one-week history of fever. Two days before his admission, he had a molar tooth extraction, and was given amoxicillin postoperatively for dental prophylaxis. He was not given any antibiotic prophylaxis before his tooth extraction. Other than fever, chills and cough, he had no other infective symptoms.

He also had significant bleeding of the tooth extraction wound causing symptomatic anemia with giddiness and dyspnea.

Physical examination revealed pyrexia (temperature of $38.6^{\circ} \mathrm{C}$ ) and stable haemodynamics. His heart sounds were crisp with a metallic first heart sound. There were no peripheral stigmata of IE.

Routine investigations showed slightly elevated inflammatory markers and severe anemia (Table 1). The chest radiograph did not reveal any opacities suggestive of septic embolism (Table 1). International normalized ratio (INR) was found to be 4.99 (latest INR before admission: 2.9). Two sets of blood culture showed no bacterial growth (Table 2). Transthoracic echocardiogram (TTE) and transoesophageal echocardiogram (TOE) were not done. 


\section{Cureus}

\begin{tabular}{|c|c|c|c|c|c|c|c|}
\hline \multirow[b]{2}{*}{ Test } & \multicolumn{5}{|l|}{ Results } & \multirow[b]{2}{*}{ Unit } & \multirow{2}{*}{$\begin{array}{l}\text { Reference } \\
\text { Level }\end{array}$} \\
\hline & First admission & $\begin{array}{l}\text { First admission } \\
\text { (Discharge) }\end{array}$ & $\begin{array}{l}\text { Second } \\
\text { admission }\end{array}$ & $\begin{array}{l}\text { Second admission } \\
\text { (Discharge) }\end{array}$ & $\begin{array}{l}\text { Third } \\
\text { admission }\end{array}$ & & \\
\hline $\begin{array}{l}\text { White blood cells } \\
\text { (WBC) }\end{array}$ & 19.79 & 12.98 & 13.99 & 11.88 & 11.06 & $10^{9} / \mathrm{L}$ & 3.37-8.38 \\
\hline $\begin{array}{l}\text { Red blood cells } \\
\text { (RBC) }\end{array}$ & 2.46 & 2.74 & 3.45 & 3.40 & 3.66 & $10^{12} / \mathrm{L}$ & $4.29-5.70$ \\
\hline Hemoglobin (Hb) & 6.8 (Baseline Hb: 8-10) & 7.4 & 9.3 & 8.4 & 9.0 & $\mathrm{~g} / \mathrm{dL}$ & $13.3-16.6$ \\
\hline Hematocrit & 19.9 & 23.1 & 28.5 & 27.1 & 28.7 & $\%$ & $41.3-52.1$ \\
\hline MCV & 80.9 & 84.3 & 82.6 & 79.7 & 78.4 & $\mathrm{fL}$ & 86.7-102.3 \\
\hline $\mathrm{MCH}$ & 27.6 & 27 & 27 & 24.7 & 24.6 & $\mathrm{pg}$ & 27.1-32.4 \\
\hline $\mathrm{MCHC}$ & 34.2 & 32 & 32.6 & 31 & 31.4 & $\mathrm{~g} / \mathrm{dL}$ & $29.7-33.1$ \\
\hline Platelets & 315 & 249 & 348 & 385 & 424 & $10^{9} / \mathrm{L}$ & $172-378$ \\
\hline MPV & 9.6 & 9.2 & 9.4 & 9.4 & 9.4 & $\mathrm{fL}$ & $9.2-12.0$ \\
\hline RDW & 14.8 & 15.3 & 15.2 & 15.4 & 15.1 & $\%$ & $12.2-14.8$ \\
\hline Sodium & 135 & 137 & 140 & 138 & 139 & $\mathrm{mmol} / \mathrm{L}$ & $135-145$ \\
\hline Potassium & 4.5 & 4 & 4.1 & 3.9 & 4.1 & $\mathrm{mmol} / \mathrm{L}$ & $3.5-5.1$ \\
\hline Chloride & 99 & 100 & 103 & 102 & 101 & mmolL & $96-108$ \\
\hline Bicarbonate & 22 & 23 & 23 & 23 & 23 & $\mathrm{mmol} / \mathrm{L}$ & 23-29 \\
\hline Creatinine & 111 & 107 & 114 & 125 & 119 & umol/L & $59-104$ \\
\hline Urea & 8.6 & 6.2 & 4.7 & 2.3 & 4.8 & $\mathrm{mmol} / \mathrm{L}$ & $2.8-7.6$ \\
\hline Anion gap & 17.9 & 18.6 & 17.8 & 17.1 & 19.0 & & $8-16$ \\
\hline Albumin & 30 & & 37 & & 40 & $g / L$ & $35-50$ \\
\hline Bilirubin, total & 7 & & 14 & & 17 & umol/L & $3-21$ \\
\hline $\begin{array}{l}\text { Alanine } \\
\text { aminotransferase }\end{array}$ & 17 & & 27 & & 19 & $u / L$ & $10-44$ \\
\hline $\begin{array}{l}\text { Aspartate } \\
\text { aminotransferase }\end{array}$ & 17 & & 18 & & 20 & $u / L$ & $10-34$ \\
\hline $\begin{array}{l}\text { Alkaline } \\
\text { phosphatase }\end{array}$ & 59 & & 74 & & 75 & $u / L$ & $45-122$ \\
\hline $\begin{array}{l}\text { Gamma-glutamyl } \\
\text { transferase }\end{array}$ & 81 & & 113 & & 73 & $u / L$ & $11-50$ \\
\hline C-reactive protein & 16.6 & & 52 & 15.1 & 10.2 & $\mathrm{mg} / \mathrm{L}$ & $1-5$ \\
\hline Procalcitonin & 0.22 & & 0.15 & & & $\mathrm{ng} / \mathrm{mL}$ & $0.5-2$ \\
\hline ograp & $\begin{array}{l}\text { No consolidation, pleural effusion } \\
\text { or pulmonary embolism }\end{array}$ & & & & & & \\
\hline
\end{tabular}

\section{TABLE 1: Trend of inflammatory markers and other investigations.}

MCV: Mean corpuscular volume; MCH: Mean corpuscular hemoglobin; MCHC: Mean corpuscular hemoglobin concentration; MPV: Mean platelet volume; RDW: Red cell distribution width. 


\section{Cureus}

\begin{tabular}{|l|l|l|l|l|}
\hline $\begin{array}{l}\text { Admission } \\
\text { (Date) }\end{array}$ & $\begin{array}{l}\text { First admission } \\
(\mathbf{1 9 / 3 / 1 8 )}\end{array}$ & $\begin{array}{l}\text { Second admission } \\
(\mathbf{1 / 4 / 1 8 )}\end{array}$ & $\begin{array}{l}\text { Second admission (2/4/18) } \\
\text { (11/4/18) }\end{array}$ & Two sets negative \\
\hline $\begin{array}{l}\text { Blood culture } \\
\text { results }\end{array}$ & Two sets negative & Two sets negative & $\begin{array}{l}\text { First and second sets grew Parvimonas micra } \\
\text { from anaerobic culture }\end{array}$ & Two \\
\hline
\end{tabular}

TABLE 2: Blood cultures during the three admissions.

He was given 4 units of packed cell transfusions for his symptomatic anemia and oral vitamin $\mathrm{K}$ for warfarin reversal. Adrenaline gauze packing and tranexamic acid gargle were given for hemostasis of the tooth extraction wound. He was started on amoxicillin/clavulanic acid for dental prophylaxis. He remained afebrile in the ward and was discharged. INR before discharge was 2.32 .

One week later, he was admitted for another episode of fever. This time, the first two sets of blood culture again did not reveal any bacterial growth. However, the third and fourth sets of blood culture were positive and grew Parvimonas micra (Table 2). TTE showed a stable MVR with no vegetation and normal function of the MVR. However, TOE showed that the MVR had at least two vegetations, with a new severe mitral regurgitation (MR) (Figure 1).

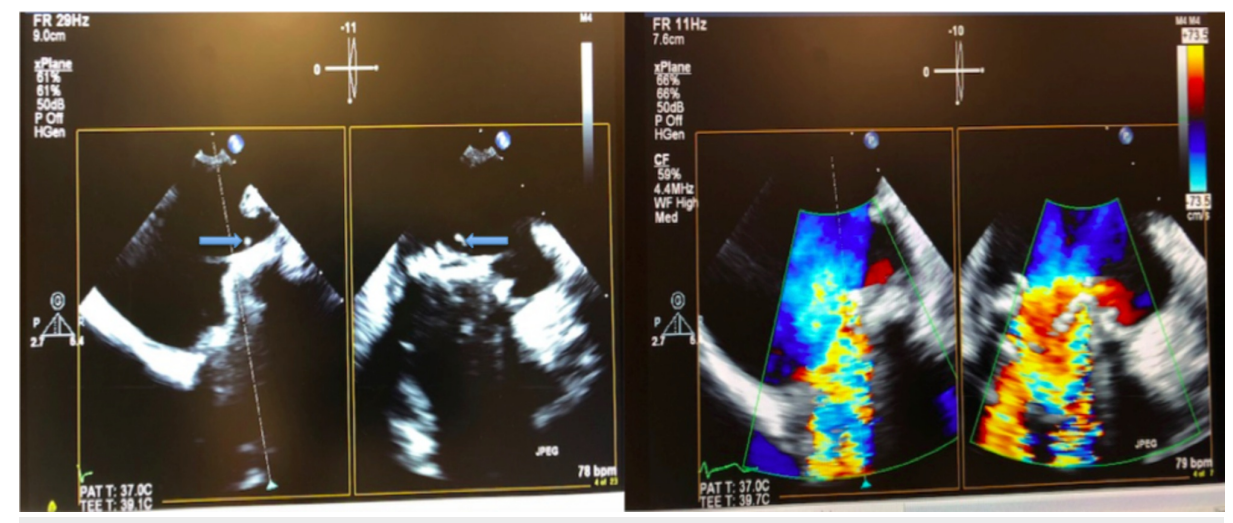

FIGURE 1: (Left) Mobile friable vegetations arising from the mitral prosthetic valve. (Right) Severe mitral regurgitation with torrential back flow across the prosthetic mitral valve demonstrated by Colour Doppler.

He was referred to the cardiologist and the infectious disease (ID) specialist. Initial antibiotic treatment was ceftriaxone and vancomycin. After two repeated sets of negative blood culture (Table 2), antibiotic was switched to penicillin $\mathrm{G}$ with the intention to complete a six-week course.

However, one month later, he was readmitted for exertional dyspnea and orthopnea. He had no fever. Inflammatory markers were unremarkable (Table 1). TTE showed a normal MVR again and was unable to quantify the severity of the MR, but unchanged mean mitral valve pressure gradient (MVPG). TOE further showed shrinkage of vegetations but severe MR, and also increased MVPG.

Penicillin G was continued. He was given diuretic for his heart failure. After consulting the cardiothoracic surgeon, the patient underwent a repair operation of the mitral paravalvular leak. Intraoperative tissue culture showed no bacterial growth. Postoperative blood culture was negative.

He remained stable after repair of his MVR.

\section{Discussion}

Parvimonas micra is part of the normal commensal flora of the gastrointestinal tract and the gingival crevice, and has been implicated in infections of the periodontal area, soft tissue and bone [2]. Prosthetic valves, dental procedures and infections, septic arthritis, and genitourinary infections are predisposing conditions for IE caused by Parvimonas micra [1].

IE caused by anaerobic bacteria remains uncommon but carries a high mortality rate of 21-43\% [1]. Mycotic aneurysms are a common complication with anaerobic IE. Other complications include valvular destruction, 
aortic ring abscess, aortitis, cardiogenic shock, dysrhythmia, and septic shock [1].

The subacute presentation of anaerobic IE can delay the diagnosis $[1,4]$. This may explain the high rate of complications and frequent need for surgery, as observed in our case.

Minces et al. noted a high rate of valvular complications in Peptostreptococcus IE [4]. Thirty-five percent of the cases required surgery. The duration of symptoms prior to diagnosis could last as long as an average of seven weeks, and as many as $45 \%$ of the cases had persistently negative blood cultures [4]. The subacute presentation of Parvimonas micra IE can lead to delays in diagnostic cardiac imaging [5]. Time to definitive echocardiogram (TTE or TOE) has been found to be an important predictor of valve destruction, embolization, and subsequent valve surgery [5]. In our patient, cardiac imaging was not done during the first admission due to the subtle nature of his presentation in the absence of classical clinical features such as new heart murmurs, embolic complications, or vascular or immunologic phenomena, along with negative blood cultures.

We found that even with improving inflammatory markers (Table 1), negative repeated blood cultures (Table 2), and shrinkage of vegetations, our patient developed severe valve dysfunction requiring surgery. This reveals that Parvimonas micra is aggressive bacteria that can lead to severe valve dysfunction despite appropriate antibiotics. Hence Parvimonas micra IE is an infection that requires closer monitoring. Identification of Parvimonas micra in blood cultures should prompt careful evaluation, particularly considering the subacute presentation, and high morbidity, of this infection.

Repeat echocardiograms including ongoing surveillance echocardiograms, particularly TOEs, are suggested. In our patient, TOE was necessary in the diagnosis of IE while TTE was negative during both the second and third admissions. This is not surprising as the sensitivity for the diagnosis of vegetations in native and prosthetic valves is $70 \%$ and $50 \%$, respectively, for TTE and $96 \%$ and $92 \%$, respectively, for TOE [6].

Surveillance echocardiogram is not only helpful in monitoring regression of vegetations, but is necessary in detecting new silent complications, including cardiac and valvular morphology and function, especially given the hostile course of Parvimonas micra IE. Young et al. reported a case of Parvimonas micra IE who developed severe native valve endocarditis complicated by aortic valvular destruction and perivalvular abscess, requiring emergent cardiac surgery with a protracted intensive care unit (ICU) course following surgery [7]. Our two cases reiterate the aggressive nature of this infection.

Interestingly, our patient was not given antibiotic prophylaxis before his tooth extraction. In the 2015 European Society of Cardiology (ESC) guidelines [6], antibiotic prophylaxis should only be considered for patients at highest risk for endocarditis, including: 1 . Patients with any prosthetic valve, 2 . Patients with a previous episode of IE, and 3. Patients with congenital heart disease, who are undergoing dental procedures requiring manipulation of the gingival or periapical region of the teeth or perforation of the oral mucosa, and is not recommended in other situations. The recommended prophylaxis is a single dose of amoxicillin or clindamycin if penicillin-allergic 30-60 minutes before the procedure. Given that prosthetic valves and dental procedures are predisposing conditions for IE caused by Parvimonas micra [1], antibiotic prophylaxis may have prevented this protracted episode of Parvimonas micra IE in our patient.

\section{Conclusions}

In conclusion, our case report demonstrates that Parvimonas micra IE is rare but associated with significant morbidity. In light of the subacute presentation of Parvimonas micra IE, the early use of cardiac imaging (TTE or TOE) despite subtle clinical features and negative blood cultures, with a low threshold for TOE, might be beneficial in a select group of patients with high index of suspicion, namely patients predisposed with prosthetic valves and recent dental procedures.

\section{Additional Information \\ Disclosures}

Human subjects: Consent was obtained by all participants in this study. Conflicts of interest: In compliance with the ICMJE uniform disclosure form, all authors declare the following: Payment/services info: All authors have declared that no financial support was received from any organization for the submitted work. Financial relationships: All authors have declared that they have no financial relationships at present or within the previous three years with any organizations that might have an interest in the submitted work. Other relationships: All authors have declared that there are no other relationships or activities that could appear to have influenced the submitted work.

\section{References}

1. Brook I: Infective endocarditis caused by anaerobic bacteria. Arch Cardiovasc Dis. 2008, 101:665-676. 10.1016/j.acvd.2008.08.008

2. Murphy EC, Frick IM: Gram-positive anaerobic cocci--commensals and opportunistic pathogens. FEMS 


\section{Cureus}

Microbiol Rev. 2013, 37:520-553. 10.1111/1574-6976.12005

3. Tindall BJ, Euzeby JP: Proposal of Parvimonas gen. nov. and Quatrionicoccus gen. nov. as replacements for the illegitimate, prokaryotic, generic names Micromonas Murdoch and Shah 2000 and Quadricoccus Maszenan et al. 2002, respectively. Int J Syst Evol Microbiol. 2006, 56:2711-2713. 10.1099/ijs.0.64338-0

4. Minces LR, Shields RK, Sheridan K, Ho KS, Silveira FP: Peptostreptococcus infective endocarditis and bacteremia. Analysis of cases at a tertiary medical center and review of the literature. Anaerobe. 2010, 16:327-330. 10.1016/j.anaerobe.2010.03.011

5. Young WJ, Jeffery DA, Hua A, et al.: Echocardiography in patients with infective endocarditis and the impact of diagnostic delays on clinical outcomes. Am J Cardiol. 2018, 122:650-655. 10.1016/j.amjcard.2018.04.039

6. Habib G, Lancellotti P, Antunes MJ, et al.: 2015 ESC guidelines for the management of infective endocarditis: the task force for the management of infective endocarditis of the European Society of Cardiology (ESC). Endorsed by: European Association for Cardio-Thoracic. Eur Heart J. 2015, 36:3075-3128. 10.1093/eurheartj/ehv319

7. Gomez CA, Gerber DA, Zambrano E, Banaei N, Deresinski S, Blackburn BG: First case of infectious endocarditis caused by Parvimonas micra. Anaerobe. 2015, 36:53-55. 10.1016/j.anaerobe.2015.10.007 